\title{
Revisão de literatura: Intervenções sobre saúde e educação no contexto escolar
}

\author{
Literature review: Interventions on health and education in the school context \\ Revisión de la literatura: Intervenciones en salud y educación en el contexto escolar
}

Recebido: 30/06/2021 | Revisado: 08/07/2021 | Aceito: 31/07/2021 | Publicado: 03/08/2021

\author{
Patrícia da Silva Dias \\ ORCID: https://orcid.org/0000-0002-0212-7780 \\ Universidade Federal do Pampa, Brasil \\ E-mail: prof.patriciadias@gmail.com \\ Mara Elisângela Jappe Goi \\ ORCID: https://orcid.org/0000-0002-4164-4449 \\ Universidade Federal do Pampa, Brasil \\ E-mail: maragoi@unipampa.edu.br
}

\begin{abstract}
Resumo
Fomentar as temáticas relacionadas à saúde no ambiente escolar é uma prática pedagógica imprescindível no que se refere ao contexto vivencial dos indivíduos na fase da adolescência. É importante que o corpo docente escolar tenha a sensibilidade para abordar a temática em sala de aula com conhecimento teórico e com senso de acolhimento às angústias trazidas pelos jovens estudantes. Na reflexão sobre esse assunto e todas as suas nuances, surgiu a necessidade de realizar um estudo de revisão bibliográfica no qual se objetiva trazer à luz do conhecimento trabalhos relacionados às intervenções em espaços escolares referentes à temática saúde e a sua relação com a educação formal. Com a finalidade de apreciar e categorizar a natureza dos trabalhos realizados acerca da temática, exibe-se aqui um estudo bibliográfico de natureza qualitativa de 34 produções acadêmico-científicas com estratos Qualis/Capes A1 publicadas entre os anos de 2011 a 2020, que foram divulgadas em nove periódicos nacionais e internacionais. A partir da leitura dos artigos, emergiram categorias de análise que foram tratadas pela Análise de Conteúdo de Bardin, sendo elas: (i) Saúde e Escola (ii) Adolescência e Saúde; e (iii) Adolescência e Comportamento de Risco em Saúde. Ao finalizar este trabalho, considera-se importante a relação estabelecida entre saúde e educação. É a partir das ações educacionais que se pode desenvolver uma atitude consistente em relação aos cuidados com o corpo e a mente e, assim, promover a qualidade de vida entre os estudantes da Educação Básica.
\end{abstract}

Palavras-chave: Adolescentes; Comportamento de risco; Prevenção; Conhecimento; Saúde.

\begin{abstract}
Fostering health-related themes in the school environment is an essential pedagogical practice with regard to the living context of individuals in adolescence. It is important that the school faculty has the sensitivity to address the issue in the classroom with theoretical knowledge and a sense of acceptance of the anxieties brought by young students. In reflecting on this subject and all its nuances, there was a need to carry out a literature review study which aims to bring to light works related to interventions in school spaces related to health and its relationship with formal education. In order to appreciate and categorize the nature of the work carried out on the subject, a bibliographical study of a qualitative nature of 34 academic-scientific productions with Qualis/Capes A1 strata published between 2011 and 2020, which were published in nine national and international journals. From the reading of the articles, categories of analysis emerged that were treated by Bardin's Content Analysis, namely: (i) Health and School (ii) Adolescence and Health; and (iii) Adolescence and Health Risk Behavior. At the end of this work, the relationship established between health and education is considered important. It is from educational actions that a consistent attitude can be developed in relation to caring for the body and mind and, thus, promoting quality of life among Basic Education students.
\end{abstract}

Keywords: Adolescents; Risk behavior; Prevention; Knowledge; Health.

\section{Resumen}

La promoción de temas relacionados con la salud en el ámbito escolar es una práctica pedagógica fundamental en relación con el contexto de vida de las personas en la adolescencia. Es importante que el profesorado de la escuela sea sensible para abordar el tema en el aula con conocimientos teóricos y un sentido de aceptación de las inquietudes planteadas por los jóvenes estudiantes. Reflexionando sobre esta temática y todos sus matices, surgió la necesidad de realizar un estudio de revisión de la literatura que tiene como objetivo sacar a la luz trabajos relacionados con intervenciones en espacios escolares relacionados con la salud y su relación con la educación formal. Para evaluar y categorizar la naturaleza del trabajo desarrollado sobre el tema, se realizó un estudio bibliográfico cualitativo de 34 producciones académico-científicas con estratos Qualis / Capes A1 publicadas entre 2011 y 2020, las cuales fueron publicadas en nueve revistas nacionales e internacionales. De la lectura de los artículos surgieron las categorías de 
análisis que fueron abordadas por el Análisis de Contenidos de Bardin, a saber: (i) Salud y Escuela (ii) Adolescencia y Salud; y (iii) Adolescencia y conductas de riesgo para la salud. Al final de este trabajo, se considera importante la relación que se establece entre salud y educación. Es a partir de acciones educativas que se puede desarrollar una actitud coherente en relación al cuidado del cuerpo y la mente y, así, promover la calidad de vida de los estudiantes de Educación Básica.

Palabras clave: Adolescentes; Conducta de riesgo; Prevención; Conocimiento; Salud.

\section{Introdução}

A escola é a instituição social pela qual todos os indivíduos, teoricamente, permanecem por um período de tempo de suas vidas; uma instituição que a priori deve estar voltada para as pessoas e seu desenvolvimento de forma integral, na busca da melhoria da qualidade de vida em um contexto de ampla plenitude. Essa asseveração nos leva a refletir o quanto é importante tratar, no currículo escolar, de assuntos voltados ao desenvolvimento e cuidado humano, que não apenas satisfaça a legislação vigente, mas que também esteja alinhada à realidade contextualizada da comunidade na qual a escola está inserida.

Diante da variada gama de assuntos que a escola se encontra capacitada para trabalhar junto aos alunos das diferentes faixas etárias e a sua comunidade escolar na forma de extensão, tem-se a temática concernente à saúde, que, impacta diretamente na qualidade de vida dos indivíduos e de suas famílias. Frente a isso, são os professores que têm a incumbência de desenvolver projetos educativos ou aderir a programas institucionais de saúde que se dispõem a levar aos discentes conhecimentos pertinentes aos cuidados com a saúde do corpo e a da mente. Nesse caminhar de promoção à saúde na escola, profissionais da saúde, da educação, pais, alunos e demais membros da comunidade devem estar integrados no esforço de transformar a escola em um ambiente saudável e que tenha entre as suas metas promover ações de cuidado com o corpo e mente.

Em documentos oficiais, como nos Parâmetros Curriculares Nacionais-PCN (Brasil, 1997), há tópico relacionado ao tema transversal saúde, sugerindo que a escola incorpore os princípios de promoção da saúde indicados pela Organização Mundial da Saúde (OMS), com o objetivo de promover a saúde e o aprendizado em todos os aspectos vivenciais do aluno quanto aos cuidados consigo e com os outros, enfatizando o conceito de alteridade, que deve estar presente em todas as relações humanas. É importante disseminar os conhecimentos relacionados à saúde, visto que, é um aprendizado que gera consequências positivas, pois permite a busca por um modo de vida saudável que, consequentemente, levará à conscientização quanto à prevenção de doenças e o autocuidado, bem como, o cuidado com o entorno e contexto no qual se vive. Logicamente isso poderá acontecer se o indivíduo que recebeu as devidas informações, coloque-as em prática e transforme seu meio de modo positivo quanto à melhora do seu cotidiano.

A partir do pressuposto de que para transformar o meio onde se está inserido, é necessário conhecer e aprender, este artigo de revisão bibliográfica tem por objetivo trazer à luz do conhecimento trabalhos relacionados às intervenções em espaços escolares referentes à temática saúde e a sua relação com a educação formal.

A opção por trabalhar com esta temática ocorreu pelo fato de considerar importante refletir acerca de aspectos relacionados aos cuidados referentes à saúde física e emocional dos alunos que frequentam a escola.

Casemiro et al. (2014) afirmam que a escola tem representado um importante local para o encontro entre saúde e educação abrigando amplas possibilidades de iniciativas. Sendo assim, os pesquisadores ainda afirmam que as ações de diagnóstico clínico e/ou social, estratégias de triagem e/ou encaminhamento aos serviços de saúde especializados ou de atenção básica, atividades de educação em saúde e promoção da saúde ocorrem dentro do ambiente escolar e sob o olhar do professor.

Muitas vezes, no ambiente escolar, os alunos não reconhecem a importância do autocuidado e prevenção de doenças, o que os leva, muitas vezes, a cair em situações de risco que poderiam ser evitadas, caso fossem alertados eficientemente na própria escola por meio da abordagem das temáticas relacionadas à saúde. 


\section{Metodologia}

De natureza predominantemente qualitativa (Bogdan \& Biklen, 1994; Günther, 2006), o presente trabalho se caracteriza como pesquisa bibliográfica que, segundo Gil (2020), vale-se de materiais já organizados com a finalidade de perceber o que já foi desenvolvido sobre uma determinada temática que se pretende avaliar mais densamente.

\subsection{Seleção dos documentos submetidos à análise}

Com o intuito de discorrer de forma aprofundada a respeito da temática do estudo em questão, foram adotados critérios para selecionar de forma apropriada e objetiva os periódicos científicos, assim como os artigos a serem analisados para a construção da presente revisão de literatura que versa sobre a interface da temática saúde e educação. Com base no objetivo geral, os documentos estudados abordam a relação da saúde com a educação em âmbito escolar levando em conta como o assunto é tratado na escola e como os professores e alunos percebem a importância em se pensar sobre saúde e autocuidado.

Nesse sentido, elegeu-se, primeiramente, periódicos nas áreas de Educação e Saúde com atributos de produção intelectual dos programas de pós-graduação (QUALIS), designada a partir de um conjunto de procedimentos estipulados pela Coordenação de Aperfeiçoamento de Pessoal de Nível Superior (CAPES), tenha sido classificada no estrato Qualis A1, publicados entre os anos de 2011 a 2020. Além dos periódicos brasileiros, também se utilizou dois periódicos espanhóis voltados à divulgação de pesquisas direcionadas à educação.

Os periódicos selecionados apresentavam em seus títulos os seguintes termos: saúde, educação, adolescente, escola, condutas de risco, currículo, nutrição, sexualidade, violência e drogas. Dentre os periódicos selecionados no primeiro estágio da presente pesquisa ( $n=9$ ), excluiu-se aqueles que não apresentavam publicações nos últimos 10 anos; os que não aceitassem acesso integral ao conteúdo, inclusive os que possibilitavam o download do material, e os que estivessem em desarmonia com o desígnio desse trabalho científico.

As investigações foram realizadas pela leitura dos títulos e resumos dos artigos, em alguns casos, leitura do documento na íntegra e pela procura pelas expressões: saúde, educação, adolescência e escola. Essas palavras-chave foram escolhidas por serem as que remetem ao assunto ao qual se procurava e ao qual se dá o interesse para justificar o presente trabalho.

Em um primeiro momento foram catalogados 130 artigos voltados para a temática em questão. Desses, após a leitura dos resumos e análise das palavras-chave mais recorrentes, foram selecionados 34 artigos para leitura na íntegra e categorização da temática.

A Tabela 1 apresenta os periódicos nos quais foram extraídos os artigos, bem como a sua classificação no sistema Qualis/Capes. 
Tabela 1 - Periódicos com o número de artigos e qualificação.

\begin{tabular}{l|l|l}
\hline Periódico & $\mathrm{N}^{\circ}$ de artigos & Qualis/Capes \\
\hline Cadernos de Pesquisa & 01 & $\mathrm{~A} 1$ \\
\hline Ciênc. Educ. Bauru & 03 & $\mathrm{~A} 1$ \\
\hline Ciência \& Educação & 01 & $\mathrm{~A} 1$ \\
\hline Ciência \& Saúde Coletiva, & 03 & $\mathrm{~A} 1$ \\
\hline Didáctica dee Las Ciencias Experimentales y Sociales & 03 & $\mathrm{~A} 1$ \\
\hline Educaçao \& Realidade & 08 & $\mathrm{~A} 1$ \\
\hline Educação (UFSM) & 01 & $\mathrm{~A} 1$ \\
\hline Revista Electrónica de Enseñanza de las Ciencias & $\mathrm{O}$ & $\mathrm{A} 1$ \\
\hline Revistada Escola de Enfermagem da USP & 09 & $\mathrm{~A} 1$ \\
\hline
\end{tabular}

Fonte: Autores (2021).

Com os artigos devidamente selecionados, partiu-se para a etapa de leitura analítica para, assim, fazer com que emergissem as categorias de análise, que segundo Bardin (2011, p. 131), é uma necessidade saber por qual razão se analisa e se menciona, de modo que se possa saber como analisar. De acordo com esse pensamento, no qual se afiança a veracidade de uma hipótese em decorrência de suas ligações com outras hipóteses já reconhecidas como verdadeiras, trata-se o material encontrado por meio de compilações, recortes, agregações e enumerações, nos quais se busca chegar a uma representação de conteúdo ou de sua expressão. Com isso, as leituras levam ao surgimento de categorias de análise que serão tratadas e discorridas no transcurso da próxima seção desse manuscrito.

\section{Resultados e Discussão}

O Quadro 1, apresenta o ano de publicação, título dos artigos, as palavras-chave que foram escolhidas para a seleção dos artigos e dados da publicação. Aqui, cabe salientar que as palavras-chave, no que se refere aos artigos científicos, têm por escopo expor a abrangência de um assunto e os seus conceitos principais, sendo assim, foram selecionadas levando em conta a temática a ser abordada neste artigo quanto à saúde e educação escolar.

Quadro 1 - Titulação dos artigos, palavras-chave, autoria e autores.

\begin{tabular}{|c|c|c|c|c|}
\hline $\mathrm{N}^{\circ}$ & Ano & Título do Artigo & Palavras-chaves & Dados da publicação \\
\hline 1. & 2011 & $\begin{array}{l}\text { A saúde no cotidiano de jovens residentes } \\
\text { em um bairro popular de Belo Horizonte, } \\
\text { MG, Brasil }\end{array}$ & $\begin{array}{l}\text { Adolescente, promoção da saúde, educação } \\
\text { em saúde, enfermagem em saúde pública }\end{array}$ & $\begin{array}{l}\text { Revista da Escola de } \\
\text { Enfermagem } \\
\text { USP, 45(spe2), 1673-1678. }\end{array}$ \\
\hline 2. & 2011 & $\begin{array}{l}\text { Criação compartilhada de um jogo: um } \\
\text { instrumento para o diálogo } \\
\text { sexualidade } \\
\text { adolescentes }\end{array}$ & $\begin{array}{l}\text { Adolescência, sexualidade, educação em } \\
\text { saúde, jogo educativo, saúde reprodutiva. }\end{array}$ & $\begin{array}{l}\text { Ciência \& Educação } \\
\text { (Bauru), 17, 941-956. }\end{array}$ \\
\hline 3. & 2011 & $\begin{array}{l}\text { Programa de saúde da família e o } \\
\text { governamento das populações. }\end{array}$ & $\begin{array}{l}\text { educação em saúde, serviços de saúde, } \\
\text { sistema público de saúde. }\end{array}$ & $\begin{array}{l}\text { Educação } \& \\
\text { Realidade, 36(3), 867-882. }\end{array}$ \\
\hline 4. & 2011 & $\begin{array}{l}\text { Educação sexual na escola: implicações } \\
\text { para a práxis dos adultos de referência a } \\
\text { partir das dúvidas e curiosidades dos } \\
\text { adolescentes }\end{array}$ & educação sexual, escola, adolescência. & $\begin{array}{l}\text { Revista Electrónica de } \\
\text { Enseñanza de las } \\
\text { Ciencias, 10(1), 64-83. }\end{array}$ \\
\hline
\end{tabular}




\begin{tabular}{|c|c|c|c|c|}
\hline 5. & 2012 & $\begin{array}{l}\text { Diálogos interdisciplinares em saúde e } \\
\text { educação: a arte do cuidar }\end{array}$ & $\begin{array}{l}\text { Interdisciplinaridade } \\
\text { saúde, cura, escola } \\
\text { formação de professores. }\end{array}$ & $\begin{array}{l}\text { Educação \& Realidade, } 37 \\
\text { 107-124. }\end{array}$ \\
\hline 6. & 2012 & $\begin{array}{l}\text { Diferenças entre adolescentes do sexo } \\
\text { feminino e masculino na vulnerabilidade } \\
\text { individual ao HIV }\end{array}$ & $\begin{array}{l}\text { síndrome de imunodeficiência adquirida } \\
\text { hiv, adolescente } \\
\text { vulnerabilidade em saúde identidade de } \\
\text { gênero }\end{array}$ & $\begin{array}{l}\text { Revista da Escola de } \\
\text { Enfermagem da USP, } 46 \text {, } \\
\text { 829-837. }\end{array}$ \\
\hline 7. & 2012 & $\begin{array}{l}\text { Educação para a Inteireza do Ser - uma } \\
\text { caminhada }\end{array}$ & $\begin{array}{l}\text { educação transdisciplinar e holística, saúde, } \\
\text { fases de vida } \\
\text { convivência harmônica, desenvolvimento a } \\
\text { consciência. }\end{array}$ & $\begin{array}{l}\text { Educação \& Realidade, } 37 \\
\text { 143-159. }\end{array}$ \\
\hline 8. & 2012 & La construcción del concepto de salud. & salud, enfermedad, educación para la salud. & $\begin{array}{l}\text { Didáctica De Las Ciencias } \\
\text { Experimentales Y Sociales. } \\
26,161-175\end{array}$ \\
\hline 9. & 2013 & $\begin{array}{lll}\text { Alteridade } & \text { e } & \text { adolescência: uma } \\
\text { contribuição } & \text { da } & \text { psicanálise para a } \\
\text { educação } & & \end{array}$ & $\begin{array}{l}\text { alteridade, adolescência } \\
\text { educação, psicanálise. }\end{array}$ & $\begin{array}{l}\text { Educação \& Realidade, } 38 \text {, } \\
\text { 555-568. }\end{array}$ \\
\hline 10. & 2013 & $\begin{array}{l}\text { Biopolítica e Educação: relações a partir } \\
\text { das discursividades sobre saúde na escola }\end{array}$ & $\begin{array}{l}\text { biopolítica, educação } \\
\text { Saúde, produção de subjetividade }\end{array}$ & $\begin{array}{l}\text { Educação \& Realidade, } 38 \text {, } \\
\text { 361-381. }\end{array}$ \\
\hline 11. & 2013 & $\begin{array}{l}\text { O jovem macho e a jovem difícil: governo } \\
\text { da sexualidade no currículo }\end{array}$ & $\begin{array}{l}\text { gênero, sexualidade, governo, currículo, } \\
\text { juventude }\end{array}$ & $\begin{array}{l}\text { Educação \& Realidade, } 38 \text {, } \\
603-625 .\end{array}$ \\
\hline 12. & 2013 & $\begin{array}{l}\text { Educação e saúde no contexto escolar: } \\
\text { Saúde cardiovascular como tema gerador } \\
\text { no curso normal médio }\end{array}$ & $\begin{array}{l}\text { educação em saúde na escola, educação em } \\
\text { ciências, doenças cardiovasculares. }\end{array}$ & $\begin{array}{l}\text { Revista Electrónica de } \\
\text { Enseñanza de las Ciencias } \\
12,167-190\end{array}$ \\
\hline 13. & 2013 & $\begin{array}{l}\text { Percepção sobre sexualidade pelos } \\
\text { adolescentes antes e após a participação } \\
\text { em oficinas pedagógicas }\end{array}$ & $\begin{array}{l}\text { percepción sexualidade, adolescente, } \\
\text { oficinas pedagógicas. }\end{array}$ & $\begin{array}{l}\text { Revista Electrónica de } \\
\text { Enseñanza de las Ciencias, } \\
12,234-242\end{array}$ \\
\hline 14. & 2013 & $\begin{array}{l}\text { Percepción de la educación para la salud } \\
\text { en el personal docente y el sanitário. }\end{array}$ & $\begin{array}{l}\text { salud, educación para la salud, promoción } \\
\text { de salud, salud escolar. }\end{array}$ & $\begin{array}{l}\text { Didáctica De Las Ciencias } \\
\text { Experimentales Y Sociales. } \\
27,115-129\end{array}$ \\
\hline 15. & 2015 & $\begin{array}{l}\text { Drogas na escola: análise das vozes sociais } \\
\text { em jogo }\end{array}$ & adolescência, drogas, escola. & $\begin{array}{l}\text { Educação \& Realidade, } \\
\text { 40,253-273. }\end{array}$ \\
\hline 16. & 2017 & $\begin{array}{l}\text { A produção sobre a educação da mulher na } \\
\text { educação de jovens e adultos }\end{array}$ & $\begin{array}{l}\text { educação de jovens e adultos gênero, } \\
\text { educação de mulheres. }\end{array}$ & Educação, 42(1), 45-56. \\
\hline 17. & 2017 & $\begin{array}{l}\text { Viver através de projetos de saúde: } \\
\text { práticas de educação em saúde no Brasil }\end{array}$ & $\begin{array}{l}\text { educação, em saúde, biopolítica } \\
\text { práticas de saúde pública. }\end{array}$ & $\begin{array}{l}\text { Educação \& Realidade, } 42 \text {, } \\
\text { 961-980. }\end{array}$ \\
\hline 18. & 2017 & $\begin{array}{l}\text { Promoção da saúde de adolescentes e } \\
\text { Programa Saúde na Escola: complexidade } \\
\text { na articulação saúde e educação }\end{array}$ & $\begin{array}{l}\text { promoção da saúde adolescente, saúde } \\
\text { escolar, colaboração intersetorial }\end{array}$ & $\begin{array}{l}\text { Revista da Escola de } \\
\text { Enfermagem da USP, } 51 .\end{array}$ \\
\hline 19. & 2017 & $\begin{array}{l}\text { Professores da rede municipal de ensino e } \\
\text { o conhecimento sobre o papel da escola na } \\
\text { formação dos hábitos alimentares dos } \\
\text { escolares }\end{array}$ & $\begin{array}{l}\text { hábito alimentar } \\
\text { ensino fundamental. promoção da saúde, } \\
\text { nutrição, alimentação }\end{array}$ & $\begin{array}{l}\text { Ciência \& Educação } \\
\text { (Bauru), 23, 691-706. }\end{array}$ \\
\hline 20. & 2017 & $\begin{array}{l}\text { Formação de professoras unidocentes e o } \\
\text { tema transversal saúde: possibilidades e } \\
\text { apontamentos }\end{array}$ & $\begin{array}{l}\text { formação docente, saúde, unidocentes, } \\
\text { holismo }\end{array}$ & $\begin{array}{l}\text { Revista Electrónica de } \\
\text { Enseñanza de las Ciencias } \\
2,341-361\end{array}$ \\
\hline 21. & 2018 & $\begin{array}{l}\text { Educação sexual em escolas brasileiras: } \\
\text { revisão sistemática da literatura }\end{array}$ & educação sexual, escola, sexualidade & $\begin{array}{l}\text { Cadernos De Pesquisa } 48, \\
.550-571\end{array}$ \\
\hline
\end{tabular}




\begin{tabular}{|c|c|c|c|c|}
\hline 22. & 2018 & $\begin{array}{l}\text { Autopercepção } \\
\begin{array}{c}\text { negativa } \\
\text { associada à } \\
\text { violência }\end{array} \text { escolar em } \\
\text { adolescentes }\end{array}$ & $\begin{array}{l}\text { autoavaliação diagnóstica } \\
\text { saúde do adolescente, violência, } \\
\text { adolescente }\end{array}$ & $\begin{array}{l}\text { Ciência } \stackrel{\&}{\text { \& Saúde }} \\
\text { Coletiva,23, 2909-2916 }\end{array}$ \\
\hline 23. & 2018 & $\begin{array}{l}\text { Desafios para as políticas públicas } \\
\text { voltadas à adolescência e juventude a } \\
\text { partir da Pesquisa Nacional de Saúde do } \\
\text { Escolar (PeNSE) }\end{array}$ & $\begin{array}{l}\text { Adolescência, saúde do adolescente fatores } \\
\text { de risco violência, escolares }\end{array}$ & $\begin{array}{l}\text { Ciência \& Saúde Coletiva, } \\
\text { 23, 2879-2890 }\end{array}$ \\
\hline 24. & 2018 & $\begin{array}{l}\text { Fatores associados aos comportamentos de } \\
\text { risco à saúde entre adolescentes } \\
\text { brasileiros: uma revisão integrativa }\end{array}$ & $\begin{array}{l}\text { Adolescente, saúde do adolescente } \\
\text { comportamento adolescente } \\
\text { tomada de risco, enfermagem pediátrica }\end{array}$ & $\begin{array}{l}\text { Revista da Escola de } \\
\text { Enfermagem da USP, 52. }\end{array}$ \\
\hline 25. & 2018 & Reflexiones acerca de la salud ambiental & $\begin{array}{l}\text { promoción de la salud, educación para la } \\
\text { salud, educación ambiental, ecologismo, } \\
\text { participación ciudadana }\end{array}$ & $\begin{array}{l}\text { Didáctica De Las Ciencias } \\
\text { Experimentales Y Sociales. } \\
36,115-128 .\end{array}$ \\
\hline 26. & 2019 & $\begin{array}{l}\text { Análise moral e ética no cuidado com a } \\
\text { saúde de adolescentes cabo-verdianos e } \\
\text { brasileiros referente ao consumo de } \\
\text { cigarros, álcool, drogas e anabolizantes }\end{array}$ & $\begin{array}{l}\text { educação para a saúde adolescente } \\
\text { ensino médio, consumo de drogas } \\
\text { consumo de anabolizantes } \\
\text { questões morais, cabo verde. }\end{array}$ & $\begin{array}{l}\text { Ciênc. Educ., Bauru, 25, } \\
297-315\end{array}$ \\
\hline 27. & 2019 & $\begin{array}{l}\text { Situação sociodemográfica e de saúde em } \\
\text { adolescentes escolares segundo o sexo. }\end{array}$ & $\begin{array}{l}\text { adolescente, sexo, saúde } \\
\text { educação, enfermagem em saúde pública. }\end{array}$ & $\begin{array}{l}\text { Revista Brasileira de } \\
\text { Enfermagem, 72, 1007- } \\
1012 .\end{array}$ \\
\hline 28. & 2019 & $\begin{array}{l}\text { Análise da abordagem de temas alusivos à } \\
\text { saúde em documentos oficiais relacionados } \\
\text { às práticas educativas em Ciências da } \\
\text { Natureza }\end{array}$ & $\begin{array}{l}\text { ensino, saúde, legislação educacional, } \\
\text { orientações curriculares, literacia em saúde }\end{array}$ & $\begin{array}{l}\text { Revista Electrónica de } \\
\text { Enseñanza de las Ciencias } \\
18,79-103\end{array}$ \\
\hline 29. & 2020 & $\begin{array}{l}\text { A violência na relação de intimidade sob a } \\
\text { ótica de adolescentes: perspectivas do } \\
\text { Paradigma da Complexidade }\end{array}$ & $\begin{array}{l}\text { adolescente; violência por parceiro íntimo; } \\
\text { saúde do estudante; pesquisa qualitativa }\end{array}$ & $\begin{array}{l}\text { Revista da Escola de } \\
\text { Enfermagem da USP, } 54 .\end{array}$ \\
\hline 30. & 2020 & $\begin{array}{l}\text { Tendência temporal e fatores associados à } \\
\text { gravidez na adolescência* }\end{array}$ & $\begin{array}{l}\text { gravidez na adolescência; saúde do } \\
\text { adolescente; enfermagem obstétrica; } \\
\text { enfermagem materno-infantil. }\end{array}$ & $\begin{array}{l}\text { Revista da Escola de } \\
\text { Enfermagem da USP, } 54 .\end{array}$ \\
\hline 31. & 2020 & $\begin{array}{l}\text { Ensino de Ciências e a Saúde: Motivações } \\
\text { do consumo de drogas entre adolescentes: } \\
\text { implicações para o cuidado clínico de } \\
\text { enfermagem }\end{array}$ & $\begin{array}{l}\text { adolescente; transtornos relacionados ao uso } \\
\text { de substâncias; cuidados de enfermagem; } \\
\text { redução do dano; educação em saúde; } \\
\text { enfermagem em saúde pública. }\end{array}$ & $\begin{array}{l}\text { Revista da Escola de } \\
\text { Enfermagem da USP, } 54 .\end{array}$ \\
\hline 32. & 2020 & $\begin{array}{l}\text { O Ensino de Ciências e a Saúde: por uma } \\
\text { Docência Intercultural e Crítico-Reflexiva } \\
\text { na Escola Básica }\end{array}$ & $\begin{array}{l}\text { educação em saúde; interculturalidade; } \\
\text { reflexividade crítica; escola básica }\end{array}$ & $\begin{array}{l}\text { Ciência \& Educação } \\
\text { (Bauru), } 26 .\end{array}$ \\
\hline 33. & 2020 & $\begin{array}{l}\text { Os cuidados da Estratégia Saúde da } \\
\text { Família a um adolescente vítima de } \\
\text { bullying: uma cartografia }\end{array}$ & $\begin{array}{l}\text { saúde do adolescente, "bullying", } \\
\text { intersetorialidade, cartografia, atenção } \\
\text { primária. }\end{array}$ & $\begin{array}{l}\text { Ciência \& Saúde Coletiva, } \\
\text { 25, 353-363. }\end{array}$ \\
\hline 34. & 2020 & $\begin{array}{l}\text { Características dos Programas escolares de } \\
\text { Prevenção ao Uso de Drogas no Brasil }\end{array}$ & $\begin{array}{l}\text { prevenção, drogas, programas, saúde } \\
\text { escolar }\end{array}$ & $\begin{array}{l}\text { Ciência \& Saúde Coletiva, } \\
\text { 25,3131-3142. }\end{array}$ \\
\hline
\end{tabular}

Fonte: Autores (2021).

Diante das leituras dos artigos científicos que trazem como temática educação e saúde, observa-se que há um interesse em mostrar que a escola precisa estar dialogando com as temáticas relacionadas ao bem-estar físico e emocional dos alunos tanto no ambiente escolar, como fora dele.

A seguir trata-se das categorias deste artigo que emergiram a partir da leitura e análise: (i) A saúde e a Escola; (ii) 
Saúde e Adolescência; (iii) Adolescência e Comportamento de Risco em Saúde. Algumas vezes, o artigo analisado permeou entre uma e outra categoria, sendo que um mesmo artigo pode ter sido contemplado em mais de uma categoria de análise.

\section{(i) A Saúde e a Escola}

Esta categoria é, de fato, a que apresenta o maior número de artigos, pois relaciona de forma intrínseca a importância em trabalhar temáticas relacionadas à saúde em âmbito escolar. Foram selecionados 17 artigos acadêmicos nacionais e internacionais voltados à temática em acordo com esse assunto (Nogueira et al., 2011; Fazenda \& Souza, 2012; Gavidia \& Talavera, 2012; Barros, 2013; Lara et al.,;2013; Talavera \& Gavidia, 2013; Barros \& Colaço, 2015; Melo \& Oliveira, 2017; Brasil; et al., 2017; Rocha \& Facina, 2017; De Jesus \& Sawitzki, 2017; Furlanetto et al., 2018; Silva, Passos \& Soares, 2018; Reis, Malta \& Furtado, 2018; Moura et al., 2018; Carrasquer; et al., 2019; Neves \& Queiroz, 2020).

Nesses artigos, articulam-se temáticas de saúde e educação, como também conceitos relacionados aos cuidados de saúde no ambiente educacional e seu aparato legal desde a Constituição Federal até os Parâmetros Nacionais da Educação e da Base (BNCC). Inicialmente, segundo Lara et al. (2013), em conformidade com a OMS, a saúde é compreendida enquanto qualidade de vida e não apenas como ausência de doença, sendo a educação em saúde um espaço de produção e aplicação dos conhecimentos destinados ao desenvolvimento humano.

Assim, é necessário lembrar que ao aproximar o campo da educação com o da saúde, é preciso considerar que a história da saúde no Brasil esteve associada à cultura indígena, difundida nos ancestrais da natureza e suas divindades (até o século XIII e meados do século XIV), e depois na influência da medicina jesuítica, paralelamente à presença da habilidade de tratamento das doenças dos curandeiros (Fazenda \& Souza, 2012).

Segundo, Melo e Oliveira (2017, p. 965):

A emergência da educação sanitária no Brasil ocorreu paralelamente ao desenvolvimento político-social da Saúde Pública. No período anterior a 1923, inexistia uma relação institucionalizada entre educação e saúde. Nesse período, vivia-se a fase do saneamento do meio, do controle das moléstias transmissíveis e da polícia sanitária. Melo (1976) enumerou alguns aspectos que marcaram a década de 1920 no país: o crescimento do setor industrial; o grande contingente de imigrantes e as novas ideias trazidas da Europa exigindo novas formas de relacionamento empregadorempregado; o crescimento da classe dos trabalhadores urbanos; a participação da classe média na arena política; o entusiasmo pela escolarização e o marcante otimismo pedagógico; e o perfil epidemiológico caracterizado por doenças transmissíveis, como o impaludismo e as verminoses.

Nesse sentido, a escola foi, ao longo do tempo, considerada um ambiente propício para difundir as informações necessárias, muito embora ainda não fosse de acesso da maior parte da população. Diante disso, surge o Decreto ${ }^{\circ} 3.876$ (Brasil, 1925), no qual competia à Inspetoria de Educação Sanitária promover a formação da consciência sanitária da população em geral com o objetivo de desenvolver com toda a generalidade possível e pelos processos mais práticos, de modo a impressionar e convencer os educandos a implantar hábitos de higiene" (Melo \& Oliveira, 2017).

Com esse panorama, a escola passa a ser parceira do recém-criado centro de saúde, promovendo, assim, espaços privilegiados na produção de saberes e de práticas de educação sanitária.

Em um olhar mais amplo, entende-se que o discurso de cuidados e higiene perpassavam os muros escolares, e as mães também eram atoras sociais desse emaranhado educativo. Estudos realizados por Moreno (1946) davam conta que a prática discursiva da época buscava a ampliação de hábitos saudáveis, dando a entender caráter comportamental e individual da educação sanitária a qual tinha por objetivo ensinar os preceitos da higiene, bem como consolidá-los entre a população. E, assim, mediante ao contexto vigente, ao longo da história, a escola vem tendo um papel de parceria na busca do bem-estar em saúde da população brasileira.

Diante disso, as nações necessitaram definir em suas legislações o que querem em termos de saúde para os indivíduos 
e como devem oferecer esse direito inerente a todo e qualquer cidadão de um país. No Brasil, o direito à saúde foi inserido na Constituição Federal de 1988 no título destinado à ordem social, que tem como objetivo o bem-estar e a justiça social. Nessa perspectiva, a Constituição Federal de 1988, no seu Art. $6^{\circ}$, estabelece como direitos sociais fundamentais a educação, a saúde, o trabalho, o lazer, a segurança, a previdência social, a proteção à maternidade e à infância (Saraiva, 1983, p. 23).

Em seguida, no Art. 196, a Constituição Federal de 1988 reconhece a saúde como direito de todos e dever do Estado, garantido mediante políticas sociais e econômicas que visem à redução do risco de doença e de outros agravos e ao acesso universal e igualitário às ações e serviços para sua promoção, proteção e recuperação. Ao reconhecer a saúde como direito social fundamental, o Estado obrigou-se a prestações positivas, e, por conseguinte, à formulação de políticas públicas sociais e econômicas destinadas à promoção, à proteção e à recuperação da saúde (Martins \& Dimoulis, 2010).

No Brasil, a proposta do Ministério da Educação esboça a saúde como uma das peças-chave para a articulação entre as diferentes atividades e disciplinas escolares, bem como está a sociedade. E, entre uma das propostas, está a inclusão de temas transversais, que vem no intuito de tornar o currículo mais flexível e aberto às realidades locais e regionais, enquanto cumprimento de exigências estabelecidas pela Lei de Diretrizes e Bases da Educação Nacional (Lei n. 9.394/96) e orientações dos Parâmetros Curriculares Nacionais - PCN (Brasil, 1997) (De Jesus \& Sawitzki, 2017) que traz em suas orientações complementares, as quais não de caráter normativo, buscam implementar, de modo mais abrangente, uma orientação quanto à abordagem de temas (como a saúde) no cotidiano das escolas em uma perspectiva cidadã, mais próximo à realidade brasileira (De Jesus \& Garcia, 2019).

Ainda no campo educacional, tem-se a BNCC, documento oficial a qual norteia que é nos anos finais do Ensino Fundamental que tem como foco a percepção de que o corpo humano é um todo dinâmico e articulado, e que a manutenção e o funcionamento harmonioso desse conjunto dependem da integração entre as funções específicas desempenhadas pelos diferentes sistemas que o compõem. Além disso, destaca-se aspectos relativos à saúde, compreendido não somente como um estado de equilíbrio dinâmico do corpo, mas como um bem da coletividade, abrindo espaço para discutir o que é preciso para promover a saúde individual e coletiva, inclusive no âmbito das políticas públicas (Brasil, 2017).

No que se refere ao Ensino Médio, a BNCC traz uma ideia de contextualização social, histórica e cultural da Ciência e da Tecnologia a qual tem viés fundamental para que elas sejam compreendidas como empreendimento humanos e sociais. Nesse sentido, a temática proposta em discutir o papel do conhecimento científico e tecnológico na organização social, nas questões ambientais, na saúde humana e na formação cultural, ou seja, analisar as relações entre ciência, tecnologia, sociedade e ambiente, são fundamentais.

A contextualização dos conhecimentos da área supera a simples exemplificação de conceitos com fatos ou situações cotidianas. Sendo assim, a aprendizagem pode valorizar a aplicação dos conhecimentos na vida individual, nos projetos de vida, no mundo do trabalho, favorecendo o protagonismo dos estudantes no enfrentamento de questões sobre consumo, energia, segurança, ambiente, saúde, entre outras. (Brasil, 2017, p. 549).

Estudos dão conta de que a escola tem um papel importante na difusão da saúde e qualidade de vida visto que, quando o aluno tem o contato com boas práticas pertinentes ao seu bem-estar, ele as leva para dentro de casa e as repassa na forma de conhecimento para a família, além de promover o autocuidado e a consciência de seu próprio corpo.

Nesse contexto, Talavera e Gavidia (2013), afirmam sobre a relevância do estudo das disciplinas relacionadas com a Educação para a Saúde. Isso pode oportunizar aos jovens aprender de forma mais relevante, ativa, crítica e solidária, e que a sua aprendizagem constitua parte essencial do seu desenvolvimento e amadurecimento pessoal. Assim, é necessário que os professores possam ter conhecimentos sobre questões básicas de saúde, habilidades para desenvolver este conhecimento, que podem ser aprendidas e relações com agências, locais e organizações comunitárias que possam participar do contexto socioeducativo dos alunos (Gavidia, 1993; Oliva, 2011). 
Segundo Gavidia e Talavera (2012), a prevenção de doenças não pode se basear apenas em pesquisas microbiológicas que buscam isolar um determinado germe, mas na identificação de comportamentos que aumentam a frequência e a intensidade dos fatores de risco para contrair doenças. Os hábitos pessoais e o estilo de vida peculiar de cada um, constituem o substrato principal dos fatores de risco. Nesta dimensão, as atitudes da pessoa em relação à sua saúde, a forma como considera que pode controlar o seu comportamento, a percepção dos valores que se assumem na saúde e na capacidade para o autocuidado.

Frente a essa realidade, a escola pode ter como linha de ação trabalhar para a conscientização desses comportamentos que foram elencados pelo Sistema de Vigilância do Comportamento de Risco da Juventude dos Estados Unidos (CRS), criado em 1991, em que estão descritas seis categorias de CRS prioritários entre os jovens e jovens adultos, como lesões não intencionais e violência, consumo de tabaco, consumo de álcool e outras drogas, comportamento sexual que leva à gravidez não planejada e a doenças transmissíveis por via sexual, hábitos alimentares pouco saudáveis e inatividade física (Moura et. al, 2018).

Nessa concepção, Silva et al. (2018) enfatizam que o ambiente escolar é um local que, para além de ter o encargo de educar e reportar saberes tende, também auxilia no pleno desenvolvimento dos alunos, na promoção de valores e relações interpessoais. Tal ideia vem ao encontro das de Fazenda e Souza (2012), ao destacarem que vivenciar a cura como cuidado é praticar interdisciplinarmente o processo terapêutico na medida em que se amplia o espaço da sala de aula para a vida, em um crescimento que mescla os micros e macros territórios, onde habitam seres em constante evolução. Diante disso e segundo Neves \& Queiroz (2020) é imprescindível repensar a docência, visando responder às demandas feitas pela educação escolar, dentre elas a interculturalidade e a educação em saúde.

Nesse sentido, o universo em que a maioria dos jovens habitualmente opera, em seus primeiros anos, é em grande parte reduzido à família, escola, amigos e serviços de saúde (Arasa et al., 1991; Talavera \& Gavidia, 2013; Pueyo et al. 2016). Reis et al, 2018 afirmam que é parte da supervisão familiar saber o local onde o filho se encontra, importar-se com seus afazeres, com suas relações e seus vínculos afetivos a fim de controlar e cuidar dos mesmos. A escola, deve ser visualizada como espaço de destaque no qual colabora na construção dos comportamentos dos indivíduos, é aquela que costuma ser apontada como prioritária para a promoção da saúde para a configuração da pessoa nas diferentes dimensões (Carrasquer et al., 2019).

\section{(ii) Saúde e Adolescência}

Das leituras propostas para a escrita deste artigo, emergiu a categoria denominada Saúde e Adolescência. Dentre os 34 artigos selecionados para leitura, 11 relacionam as duas temáticas de forma intrínseca, sendo eles: (Horta \& Sena, 2011; Nogueira et al., 2011; Anjos et al., 2011; Santos \& Sadala, 2013; Barros \& Colaço, 2015; Brasil et al., 2017; Silva; et al., 2018; Reis, Malta \& Furtado, 2018; Moura et al., 2018; Marinho \& Silva, 2019; Mota et al., 2018).

Comumente, o foco está nas ações relacionadas à puberdade, como transformações físicas e psicológicas que marcam o início da adolescência, sendo esses os referenciais que têm sustentado as ações de saúde para a juventude (Horta \& Sena, 2011). É por isso que se visualiza a necessidade de compreender a saúde como uma construção que se dá no cotidiano dos jovens, em que se materializam as possibilidades e as limitações do viver, marcada também pela (in)expressividade das políticas públicas (Horta \& Sena, 2011).

Lahire (2002) considera que o jovem está mergulhado em uma pluralidade de mundos sociais e que ele deve ser compreendido como um ator plural, sujeito a princípios de socialização heterogêneos e às vezes contraditórios, tendo em vista que vive, simultânea e sucessivamente, em contextos sociais diferenciados, que trazem diferentes repercussões em seus modos de ser e de viver sua juventude, como sujeito social. 
Os estudos de Horta e Sena (2011), apontam que os jovens têm em mente que o corpo é foco das práticas de cuidado em saúde. O corpo e o cuidado do corpo constituem o eixo central para se analisar como a saúde é percebida no cotidiano da vida pelos jovens. A saúde revelou-se como a garantia das condições vitais, fundamentais para os jovens alcançarem seus projetos e desejos.

Marinho e Silva (2019) revelam que o adolescente que se percebe como sujeito de valor irá cuidar de sua saúde, procurando se afastar das condutas de risco. Porém, se esse adolescente não se percebe como um sujeito de valor pode acabar por não ter um cuidado mais acurado com sua saúde, pois não visualiza a importância no zelo para consigo. Com isso, surge a importância da autopercepção em saúde, termo utilizado por Silva et al. (2018), que se relaciona ao fato de o jovem ter uma percepção positiva ou negativa ao seu estado de saúde e cuidados consigo e com seu próprio corpo para garantir seu bem-estar.

Assim sendo, a escola é a principal instituição que acolhe os adolescentes nessa fase de desenvolvimento. Silva et al. (2018) afirmam que o ambiente escolar é um local que, para além de ter o encargo de educar e reportar saberes, tende também a auxiliar o pleno desenvolvimento dos alunos, a promoção de valores e relações interpessoais.

Quanto aos profissionais de saúde da atenção primária, Brasil et al. (2017) revelam que é importante que eles estejam atentos para o potencial dos adolescentes, com vistas ao protagonismo, que contribui para o seu cuidado e colabora com outros sujeitos na mesma faixa etária, com atitudes dialógicas.

Todas essas participações que vinculam a importância da atenção à saúde do adolescente se devem ao fato de essa parcela da população ser mais suscetível às CRS, tais como: injúrias e violências acidentais, tabagismo, uso de álcool e outras drogas, gravidez indesejada e transmissão sexual doenças, hábitos alimentares pouco saudáveis e falta de exercício físicos.

Tendo em vista a importância da temática, Reis, Malta e Furtado (2018) ressaltam em seu trabalho que o conhecimento de como vivem e se comportam os escolares possibilita mensurar a magnitude e a distribuição de importantes fatores de risco à saúde em adolescentes e jovens, em diversos aspectos. O monitoramento da saúde do adolescente é uma importante estratégia em saúde pública e a OMS preconiza a realização de inquéritos epidemiológicos nesta fase da vida, visando o acompanhamento das condições de saúde e vida e o apoio às políticas públicas.

\section{(iii) Adolescência e Comportamento de Risco em Saúde}

Ao longo das leituras dos artigos que relacionam a saúde com a educação, emergiu uma terceira categoria que focaliza os comportamentos de risco em saúde adotadas pelos adolescentes ao longo dessa fase da vida. Diante da seleção feita entre os artigos, 16 deles relacionam os comportamentos de risco entre os adolescentes, bem como as condutas negativas que levam a situações que podem comprometer a saúde e a qualidade de vida. São eles: (Rocha \& Fomer, 2011, Horta \& Sena, 2011; Anjos et al., 2011; Cajaíba, 2013, Barros \& Colaço, 2015; Brasil et al., 2016; Moura et al., 2018; Rocha \& Facina, 2017; Silva; et al., 2020; Mota et al., 2018; Reis; et al., 2019. Pigozi \& Machado, 2019; Soares et al., 2020; Pereira \& Sanchez, 2020; Campeiz;et al., 2020; Lopes et al., 2020)

A Conferência Internacional sobre Promoção da Saúde, realizada em Ottawa, em 1986, define promoção da saúde como:

[...] o nome dado ao processo de capacitação da comunidade para atuar na melhoria de sua qualidade de vida e saúde, incluindo uma maior participação no controle deste processo. Para atingir um estado de completo bem-estar físico, mental e social [...]. Nesse sentido, a saúde é um conceito positivo, que enfatiza os recursos sociais e pessoais, bem como as capacidades físicas. Assim, a promoção da saúde não é responsabilidade exclusiva do setor saúde, e vai para além de um estilo de vida saudável, na direção de um bem-estar global (Carta de Ottawa, 1986, p. 1).

Dessa forma, a promoção da saúde enfatiza a modificação das condições de vida e de trabalho, demandando uma abordagem intersetorial (Czeresnia \& Freitas, 2003). Ademais, aponta para a transformação dos processos individuais de 
tomada de decisão para que sejam predominantemente favoráveis à qualidade de vida e à saúde (Silveira, 2004). As ações preventivas, por sua vez, são definidas como intervenções orientadas a evitar o surgimento de doenças específicas, reduzindo sua incidência e prevalência nas populações. Para tanto, baseiam-se no conhecimento epidemiológico de doenças e de outros agravos específicos (Czeresnia \& Freitas, 2003).

O termo risco refere-se ao grau de probabilidade da ocorrência de um determinado evento (Pereira, 1995). Do ponto de vista epidemiológico, a terminologia "risco" é empregada para definir a chance de uma pessoa sadia, exposta a determinados fatores, ambientais ou hereditários, desenvolver uma doença. Os fatores associados ao aumento do risco de se desenvolver uma doença são chamados fatores de risco. Contrariamente, há fatores que conferem ao organismo a capacidade de se proteger contra a aquisição de determinada doença, sendo chamados fatores de proteção. Os fatores de risco podem ser encontrados no ambiente físico, herdados ou resultado de hábitos ou costumes próprios de um determinado ambiente social e cultural.

Nos conceitos apresentados anteriormente, voltados à saúde e fatores de risco em saúde, apresenta-se um conceito que está intrinsecamente voltado a abordagem da categoria a qual está-se discutindo, o qual se relaciona aos CRS. Segundo Moura et al. (2018), o envolvimento do indivíduo em atividades que levam ao comprometimento de sua saúde física e/ou mental pode definir o que se denominam CRS. Esses comportamentos procedem de escolhas e atitudes que tendem a impactar de forma negativa a saúde dos jovens, tornando prematuro o risco de morbimortalidade (Guedes, 2010).

Como já mencionado, foi organizado um instrumento proposto pelo Sistema de Vigilância do Comportamento de Risco da Juventude, criado em 1991 e elencou-se seis categorias de CRS prioritários entre os jovens e jovens adultos, como lesões não intencionais e violência, consumo de tabaco, consumo de álcool e outras drogas, comportamento sexual que leva à gravidez não planejada e a doenças transmissíveis por via sexual, hábitos alimentares pouco saudáveis e inatividade física (Moura et al., 2018). Para esses autores, tendo em vista a diversidade de situações consideradas perigosas à saúde de adolescentes e a necessidade de intervenção sobre elas, faz-se indispensável a realização de pesquisas que possam diagnosticar e melhor compreendam esse panorama nos diferentes cenários nacionais.

Reis et al. (2018) afirmam que conhecimento de como vivem e se comportam os escolares possibilita mensurar a magnitude e a distribuição de importantes fatores de risco à saúde em adolescentes e jovens, em diversos aspectos. Nesse sentido, WHO (2009) afirma que o monitoramento da saúde do adolescente é uma importante estratégia em saúde pública e a OMS preconiza a realização de inquéritos epidemiológicos nesta fase da vida visando o acompanhamento das condições de saúde e vida e apoiar políticas públicas.

Violência, para a OMS, caracteriza-se pelo uso intencional da força física ou do poder, real ou em ameaça, contra si próprio, contra outra pessoa, ou contra um grupo ou uma comunidade, que resulte ou tenha a possibilidade de resultar em lesão, morte, dano psicológico, deficiência de desenvolvimento ou privação (Krug et al., 2002). Segundo Silva et al. (2018, p. 2910), a OMS afirma que:

A violência é uma constante na vida de um grande número de pessoas em todo o mundo, de todas as gerações, grupos sociais e culturais, denunciando sua presença desde os espaços públicos até os privados, perpassando pelos locais de trabalho, o seio familiar, além das variadas instituições de convivência social, inclusive as escolas.

Sabe-se que a escola é um ambiente rico em interações, troca cultural, aceitação de diferenças, compartilhamento de interesses, principalmente na fase da adolescência, por isso, Silva et al. (2018) destacam em seus escritos que o ambiente escolar é um local que, para além de ter o encargo de educar e reportar saberes tende também a auxiliar o pleno desenvolvimento dos alunos, a promoção de valores e relações interpessoais. Segundo Jacobson et al. (2009), a adolescência se apresenta como uma fase de aquisição de hábitos saudáveis, bem como de exposição a situações de risco com efeitos 
significativos no presente e no futuro.

De acordo com as leituras dos artigos realizadas para essa revisão, a violência escolar apresenta-se na forma de bullying; o qual se caracteriza por opressão, tirania, agressão que pode ser física ou verbal e ainda dominação. Segundo Pigozi \& Machado (2020), o bullying é caracterizado como um conjunto de comportamentos agressivos que acontece repetidas vezes e com desequilíbrio de poder entre os envolvidos, de modo que a vítima se sente impotente perante o ato de violência. Sabe-se que, segundo Lopes Neto (2005) a ocorrência desse problema no ambiente escolar é significativa, o que causa diferentes consequências nos adolescentes vitimizados, como, por exemplo, baixo rendimento escolar, falta de vontade de ir para a escola, insegurança no ambiente escolar, medo, ansiedade, tristeza, depressão, cefaleia, desmaio, tentativa de suicídio e suicídio.

Frente a essa realidade, em seus relatos, Silva et al. (2018) alertam que o suicídio também é um tipo de violência que acomete a população adolescente sendo considerada um tipo de violência autoinflingida de causas externas e tem aumentado na população jovem das cidades brasileiras, que impacta na saúde pública, podendo ter influência do ambiente escolar. Para esses autores, é importante saber como os jovens, que por algum motivo sofrem algum tipo de violência, caracterizam sua saúde.

Outra forma de abuso que vem se difundindo entre os adolescentes atualmente refere-se à Violência nas Relações de Intimidade (VRI) que, segundo Campeiz et al. (2020), caracteriza-se pelo envolvimento em relações de intimidade abusivas, decorrentes, sobretudo, do início das relações sexuais e crença no amor romântico. A VRI pode se caracterizar como física, verbal, sexual ou psicológica/emocional e advir de um relacionamento estreito ou pessoal entre dois indivíduos. Uma das formas de violência que mais se manifesta nas relações de intimidade entre os adolescentes é conhecida como Stalking, noção que designa o ato de perseguir, ameaçar e controlar o outro indivíduo, gerando estados emocionais de medo e insegurança (Campeiz et.al, 2020). Frente a esse tipo de agressão é de fundamental importância a abordagem quanto à conscientização dessa forma de violência entre os adolescentes visto que, a mesma tem potencial para afetar e causar danos à saúde emocional dos indivíduos que porventura possa vir a sofrer esse tipo de abuso.

Segundo estudos desenvolvidos, outro fator que contribui para a ampliação das condutas de risco está ligado ao uso de drogas lícitas como no caso do cigarro e bebidas alcoólicas e drogas ilícitas.

Soares et al. (2020) destacam que o adolescente usa a droga como uma válvula de escape para os problemas gerados por uma cultura em crise que gera ansiedade, medo, dificuldades de inserção e baixa resiliência, assim como a necessidade sentida pelos jovens de se relacionarem, formarem novos vínculos sociais e afetivos, inserirem-se em grupos de pares e ter neles visibilidade. Nesse sentido, segundo os autores, o consumo de drogas lícitas ou ilícitas confere aos adolescentes o status de destemido, desinibido e a sensação de poder.

O tabagismo, desde 1993, é considerado uma dependência química decorrente do uso de substâncias psicoativas de acordo com a décima versão da Classificação Internacional de Doenças (CID-10) da OMS. Entretanto, embora seja uma patologia, constitui-se também como um dos principais fatores de risco para mais de 50 outras doenças, destacando-se as doenças cardiovasculares, as neoplasias e as doenças respiratórias obstrutivas crônicas (Brasil, 2003). Além das consequências à saúde, o tabagismo provoca enormes custos sociais, econômicos e ambientais. Em países desenvolvidos, os custos relacionados aos cuidados com as doenças associadas ao tabagismo consomem de $6 \%$ a 15\% do gasto total com saúde (Brasil, 2004).

As drogas lícitas, bebidas alcoólicas e o cigarro acabam por atrair a atenção de muitos adolescentes em busca de prazer, principalmente pelo fato de as indústrias de substâncias psicoativas realizarem investimentos pesados em espaços de propagação da oferta e da sedução do consumo dos seus produtos (Silveira; Santos \& Pereira, 2014). Marinho e Silva (2019) afirmam que é necessário investigar o pensamento dos adolescentes sobre a questão do consumo de cigarros, álcool/drogas, 
bem como, sobre a utilização de anabolizantes. Isto configura-se como uma obra necessária e importante, principalmente, para a elaboração de ações que podem ser desenvolvidas nas escolas, bem como em outros espaços educativos.

Diante desse pensamento, Elicker et al. (2015) evidenciam que há na adolescência uma maior vulnerabilidade para experimentação e uso abusivo de drogas, considerando diversos e complexos os motivos que levam ao aumento do uso dessas substâncias. Com relação à temática, Lobo e Barbosa (2017) apontam que alguns desses motivos se relacionam ao fato de a adolescência se configurar como uma fase que deixa os indivíduos mais expostos à rebeldia, curiosidade e grande influência das amizades em seu cotidiano.

Mülller, Paul e Santos (2008, p. 610), assim como Moreira, Silveira \& Andreoli (2006), ressaltam duas das principais posturas pelas quais se abordam o uso e o abuso de substâncias psicoativas no contexto escolar: "[...] a primeira que estimula a proibição, pela diminuição da oferta, com informações que se caracterizam pelo apelo moral e produção de medos, persuadindo as pessoas à abstinência; a segunda é a redução de danos [...]” visando a educação em prol à saúde.

Nessa ótica, Barros e Colaço (2015) afirmam que ao tratar das orientações gerais para prevenir o uso abusivo de drogas, tal política reafirma o papel primordial da escola, ao apontar que a efetiva prevenção resulta do comprometimento conjunto de diferentes segmentos sociais e órgãos governamentais da sociedade brasileira, de modo a multiplicar ações que incentivem a socialização de conhecimentos sobre drogas, o protagonismo juvenil e a produção de saúde. Diante dessa realidade, Pereira e Sanchez (2020) sugerem que as ações de prevenção ao uso de drogas nas escolas devem ser baseadas em evidências científicas, ou seja, que tenham apresentado resultados positivos em estudos de avaliação de eficácia ou efetividade, economizando, assim, recursos financeiros e humanos investidos em ações de pouco ou nenhum efeito. A participação da escola também figura entre as diretrizes dessa política, na medida em que, por exemplo, propõe-se a capacitação continuada de educadores e a inclusão de conteúdos referentes ao uso indevido de drogas, no Ensino Básico e Superior (Brasil, 2005). A estratégia de minorar o uso indevido de drogas ganhou evidência a partir da década de 70 do século XX. Naquele período, a Organização das Nações Unidas para a Educação, a Ciência e a Cultura (UNESCO) passaram a salientar o papel da escola como espaço da maior importância para a realização de uma abordagem preventiva ao abuso de drogas (Moreira; Silveira; \& Andreoli, 2006).Soares e Jacobi (2000) destacam a relevância da escola como local privilegiado para trabalhar prevenção às drogas pela possibilidade de acesso aos jovens e por seu lugar socialmente legitimado como instituição formadora de crianças e adolescentes.

Dando continuidade aos comportamentos de risco enumerados para essa categoria aborda-se a temática relacionada aos hábitos alimentares e prática de atividades físicas. A promoção de práticas alimentares saudáveis está inserida no contexto da adoção de estilos de vida saudáveis, sendo importante no contexto da promoção da saúde (Brasil, 2003). Levando em conta essa afirmação, faz-se necessário abordar o assunto relacionado à adoção de uma alimentação saudável e prática de atividades físicas para a promoção da saúde e qualidade de vida no ambiente escolar e fora dele.

Diante dessa realidade a OMS, visando à promoção da saúde e prevenção de doenças, lançou a iniciativa "Estratégia Global para Alimentação, Atividade Física e Saúde”, aprovada em 2004 por 191 países, destacando-se entre as ações preconizadas aquelas visando à promoção de práticas alimentares saudáveis no âmbito escolar (WHO, 2004).

Rocha e Facina (2017) revelam que, no Brasil, as diretrizes para a Promoção da Alimentação Saudável nas Escolas (Brasil, 2006), o Programa Nacional de Alimentação Escolar (PNAE) (Brasil, 2009) e a Política Nacional de Alimentação e Nutrição (PNAN) (Brasil, 2012) compreendem algumas políticas públicas que preveem, entre outras ações, a incorporação da temática alimentação saudável no Projeto Político Pedagógico das escolas, contemplando o desenvolvimento contínuo de programas de promoção de hábitos alimentares saudáveis. Diante dessa prerrogativa, a escola pode assumir a responsabilidade pela educação em saúde devido a sua função social e a sua potencialidade para o desenvolvimento de um trabalho sistematizado e contínuo (Sobral \& Santos, 2010). 
A obesidade é uma doença crônica que envolve fatores sociais, comportamentais, ambientais, culturais, psicológicos, metabólicos e genéticos. Caracteriza-se pelo acúmulo de gordura corporal resultante do excesso de consumo de calorias e/ou inatividade física (WHO, 1995; Brasil, 2004). Salienta-se que a América Latina, inclusive o Brasil, nos últimos 20 anos, apresentou uma rápida transição epidemiológica e nutricional marcada pelo aumento da prevalência da obesidade nos diversos estratos da população nas diversas classes econômicas e praticamente em todas as faixas etárias (Monteiro et al., 2000).

Diante dessa realidade, é importante trabalhar a cultura da alimentação saudável e da prática de atividades físicas entre os alunos no ambiente escolar tendo em vista a declaração de Brasil et al. (2016) que afirmam que o movimento da promoção da saúde torna-se política de saúde no Brasil, e a escola é um ambiente favorável para utilização de recursos educativos para essa finalidade.

Frente ao exposto, a promoção de atividades educativas no ambiente escolar, na qual a alimentação tem sido colocada como uma ferramenta para a promoção da saúde, constitui-se como estratégia de vital importância para o enfrentamento dos problemas de saúde do contexto atual (Azolin et al., 2010; Santos, 2005), sendo este um setor estratégico para a concretização de iniciativas de promoção da saúde (Schmitz et al., 2008). Nessa linha de pensamento (Juzwiak et al, 2013) ponderam que políticas de saúde voltadas para a promoção de hábitos alimentares saudáveis e estilos de vida ativos para crianças e adolescentes têm se tornado uma prioridade, principalmente, devido ao panorama da epidemiologia, nutrição e transições demográficas. Essa afirmativa corrobora com a opinião Mira (2007) que assegura que os professores podem se tornar aliados nesse processo por meio da educação em saúde, principalmente por fazerem parte do ambiente escolar e da realidade da comunidade, e por terem os instrumentos pedagógicos para a realização desse trabalho, pois possuem estratégias educativas necessárias para a construção integrada do conhecimento. (Bucharles, Mont’Alverne \& Catrib, 2013).

Outro ponto a ser discutido está direcionado à sexualidade no contexto escolar, o que para Cajaiba, (2013) é importante e ao mesmo tempo muito difícil de ser discutida devido à falta de informação por parte dos alunos, além da resistência encontrada por alguns pais ou devido a tabus, preconceitos, medo, despreparos e mitos que os mesmos trazem desde sua infância, em naquela época toda sociedade repudiava qualquer tentativa de abordagem desse assunto, que deveria ser reprimida para não corromper os adolescentes. Assim, essa cultura conservadora perpassa de geração a geração. Diante do exposto, a Educação Sexual voltada aos adolescentes e jovens e que se faz tão necessária para que ocorra o conhecimento aos modos de prevenção da gravidez precoce e ocorrência de infecções sexualmente transmissíveis, as ISTs.

A adolescência é um período de rápido desenvolvimento pessoal, fisiológico, social e emocional. Tal etapa compreende o aprendizado e a experiência da sexualidade e demais formas de relacionamento humano, assim como o desenvolvimento da identidade e da autoestima. Este é um período em que se aprende sobre os papéis de gênero e as relações de poder e onde ocorre o despertar da capacidade reprodutiva.

A falta de maturidade em administrar o corpo desenvolvido, ao que parece, é que tem tornado o adolescente vulnerável, sendo indispensável a presença de um adulto maduro e acolhedor (Moreira et. al, 2011). Assim sendo, a saúde do adolescente tem como características as ações e o enfoque preventivo e educativo que visam conhecer os conteúdos da atenção integral à saúde nesta fase da vida. Para que o trabalho seja bem-sucedido, as equipes podem interagir com seu público-alvo, podem respeitar sua cultura e conhecimentos adquiridos, criando condições para o crescimento de ambas as partes. O desenvolvimento adequado desses conteúdos aumenta a possibilidade de construção dos conhecimentos pela população, o que favorece o aperfeiçoamento da sociedade (Brasil, 2002).

Teoricamente, os indivíduos vivenciam a sua adolescência na escola, e por esse fato a temática sexualidade pode estar comtemplada no currículo escolar, como afirmam Moreira e Folmer (2015), ao relatarem que a educação sexual na escola possui o objetivo de proporcionar aos alunos conhecer, refletir e discutir as questões ligadas à sexualidade, tendo em vista o desenvolvimento de uma vida mais prazerosa, com consciência e liberdade nas escolhas, viabilizando uma qualidade de vida 
melhor. Ainda, se a meta é informar ou melhor, formar, a escola, destaca-se entre os grupos de referência por ser essa sua função essencial.

Quanto à abordagem das temáticas em questão, os PCNs alertam para a imediata ponderação: "Se a escola que se deseja deve ter uma visão integrada das experiências vividas pelos alunos, buscando desenvolver o prazer pelo conhecimento, é necessário que ela reconheça que desempenha um papel importante na educação para uma sexualidade ligada à vida [...]" (Brasil, 1998, p. 114).

Sendo assim, o Ministério da Educação (MEC), por meio dos PCNs (Brasil, 1998), que norteiam a organização curricular, apresenta a sexualidade na seção de Ciências da Natureza, especificamente, no que se refere ao bloco temático "ser humano e saúde". Juntamente com as recomendações desta seção de Ciências da Natureza, há um livro adicional que retrata os temas transversais, nominados Ética, Pluralidade Cultural, Orientação Sexual, Meio Ambiente, Saúde e Trabalho e Consumo, e quanto ao aspecto relacionado à dispõe que:

[...] o professor deve então entrar em contato com questões teóricas, leituras e discussões sobre as temáticas específicas de sexualidade e suas diferentes abordagens; preparar-se para intervenção prática o qual deve ocorrer de forma continuada e sistemática, constituindo, portanto, um espaço de reflexão sobre valores e preconceitos dos próprios envolvidos no trabalho de Orientação Sexual (Brasil, 1998, p. 123).

A temática sexualidade também está embasada nas Diretrizes Curriculares Nacionais da Educação Básica, que traz a seguinte assertiva:

Os adolescentes, nesse período de vida, modificam as relações sociais e os laços afetivos, intensificando as relações com os pares de idade e as aprendizagens referentes à sexualidade e às relações de gênero, acelerando o processo de ruptura com a infância na tentativa de construir valores próprios. Ampliam-se suas possibilidades intelectuais, o que resulta na capacidade de realização de raciocínios mais abstratos. Os alunos se tornam crescentemente capazes de ver as coisas a partir do ponto de vista dos outros, superando, dessa maneira, o egocentrismo próprio da infância. Essa capacidade de descentração é importante na construção da autonomia e na aquisição de valores morais e éticos (Brasil, 2013, p. 110).

Nesse sentido, a BNCC indica, com relação à temática sexualidade, que:

Nos anos finais, são abordados também temas relacionados à reprodução e à sexualidade humana, assuntos de grande interesse e relevância social nessa faixa etária, assim como são relevantes, também, o conhecimento das condições de saúde, do saneamento básico, da qualidade do ar e das condições nutricionais da população brasileira (Brasil, 2017, p.325).

Contudo, o professor tem um papel fundamental nesse período de transição imposta pela vida, pois sugere-se que "[...] os professores atentos a esse processo de desenvolvimento, buscarão formas de trabalho pedagógico e de diálogo com os alunos, compatível com suas idades, lembrando sempre que esse processo não é uniforme e nem contínuo" (Brasil, 2013, p 110).

A preocupação em tratar esse assunto nesse trabalho está ligada ao fato de que, segundo Mota et al. (2019), essa fase se constitui em um momento peculiar para o desenvolvimento humano. É um período de mudanças anatômicas, fisiológicas e sociais relacionadas ao surgimento das características sexuais, a descoberta da sexualidade, a estruturação da personalidade, a adaptação ambiental e a integração social. Neste transcurso, os indivíduos estão vulneráveis a agravos que comprometem sua saúde e qualidade de vida, podendo inclusive levá-los à morte. Esses agravos se apresentam de forma distinta em adolescentes de diferentes sexos. De modo geral, as meninas se encontram mais expostas à exploração sexual, enquanto os meninos, à violência urbana. 
Diante dessa afirmativa, convém salientar que a escola exerce um papel fundamental quanto à abordagem dessa temática, pois, de acordo com Mota et al. (2018), o uso não frequente de preservativo remete à vulnerabilidade do público em adquirir ISTs e/ou uma gravidez indesejada. Pesquisas cientificas voltadas a esse assunto apontam para a fragilidade no conhecimento acerca das ISTs por adolescentes e adultos jovens. Tal evidência corrobora para a necessidade de educação em saúde como estratégia de favorecer o conhecimento e a tomada de decisão consciente pelo adolescente. Dessa forma, reflete-se quanto à questão de trabalhar a conscientização quanto a esse comportamento de risco adotado pelos adolescentes e que pode trazer sérios prejuízos a qualidade de vida e comprometimento da saúde. Frente a essa realidade, a vulnerabilidade dos adolescentes é fruto da interação dos fatores individuais com fatores sociais nos quais estão envolvidos, podendo tornar-se mais vulneráveis ou menos, dependendo de sua capacidade de reinterpretar criticamente mensagens sociais de perigo (Anjos et al., 2011). Frente a essa situação, se faz necessário estimular os jovens a pensar criticamente sobre a realidade de suas vidas para que tenham autonomia em suas escolhas, reduzindo assim sua vulnerabilidade.

Quanto à gravidez indesejada, Lopes et. al (2020) afirmam que complicações gestacionais e associadas ao parto são consideradas a segunda causa de morte entre adolescentes e reforça que entre os nascidos de mães adolescentes.

Nessa linha de pensamento, Mota et al. (2018) acrescentam a necessidade de estratégias que intervenham no processo de construção da desigualdade de gênero, a qual subjuga, especialmente, as mulheres, visto que interfere em seu modo de ser e viver, comprometendo sua saúde e qualidade de vida. Salienta-se a importância da educação como uma oportunidade de mudança de cultura, sendo a escola um espaço singular para tal.

Quanto ao autocuidado e desvio das condutas de risco em saúde, Marinho e Silva (2019) defendem a ideia de que o sentimento de obrigatoriedade moral depende da expressão do valor do próprio "eu". Evidencia-se que o sentimento de autorrespeito acaba unindo os planos moral e ético, considerando que o sujeito que respeita a moral, respeita a si próprio. Entende-se que o adolescente que se percebe como sujeito de valor irá cuidar de sua saúde, procurando se afastar das condutas de risco. Porém, se esse adolescente não se percebe como um sujeito de valor pode acabar por não ter um cuidado mais acurado com sua saúde, pois não visualiza importância no zelo para consigo.

Na concepção de Boff (1999), cuidar é a característica básica do ser humano e pressupõe atitude de convivência, interação e comunicação. As relações devem ocorrer a partir da perspectiva do sujeito-sujeito, não da perspectiva do sujeitoobjeto. Com isso, é importante salientar mais uma vez que na escola as interações ocorrem de maneira que os estudantes podem e tem a perspectiva de construir conhecimentos e conscientização quanto às maneiras de prevenção e evitar adotar as condutas de risco descritas nesse trabalho.

\section{Considerações Finais}

A partir da leitura atenta dos artigos selecionados, verifica-se a importância de articular saúde e escola, como também conceitos relacionados aos cuidados de saúde no ambiente educacional e as bases legais que amparam essa temática desde a Constituição Federal até os PCNs e da BNCC.

A categoria Saúde e a escola remete a articulação das temáticas saúde e educação, enfocando a importância dos cuidados com o bem-estar individual e coletivo no ambiente educacional, amparado por bases legais. Ao longo da reflexão tem-se o contexto histórico da inserção do tema saúde nas escolas que surge de forma tímida e finalmente se fortalece com a Constituição Federal de 1988 e com a LDB (Lei 9.394/98). Nessa categoria percebe-se a importância que tem o engajamento dos professores e de toda a comunidade escolar para buscar formas de desenvolver atividades pedagógicas voltadas à saúde dos adolescentes na promoção da qualidade de vida de forma global, o que afeta o contexto social e familiar em que cada indivíduo se insere.

Observar-se que a categoria Adolescência e Saúde nos traz a reflexão sobre o valor de pensar sobre a interligação da 
fase da adolescência e situações de promoção de saúde no contexto em que os indivíduos estão inseridos. Nota-se que é na fase da adolescência que surgem as maiores dúvidas em relação à saúde física e psicológica, bem como as transformações corporais, e é nesse momento da vida que os jovens precisam ser orientados para darem seus passos de forma mais consciente e sensata. É importante o papel dos agentes de saúde e dos professores para a orientação dos adolescentes nessa fase da vida.

Quanto aos comportamentos de risco em saúde, constata-se a importância de trabalhar as temáticas relacionadas a violência, drogas, sedentarismo, alimentação saudável e sexualidade no ambiente escolar de forma a promover uma conscientização a respeito dos cuidados em saúde e, ainda, se reconhece que há profissionais e trabalhos voltados para essa finalidade.

Por fim, ressalta-se que revisões como estas servem de base para a identificação trabalhos que estão sendo realizados sobre educação e saúde, adolescência e comportamentos de risco em saúde, pois norteiam novos trabalhos e novas possibilidades de promover a cultura do cuidado do corpo e da mente, bem como a qualidade de vida entre os estudantes da Educação Básica.

\section{Referências}

Anzolin, C., Ouriques, C. M., Höfelmann, D. A., \& Mezadri, T. (2010). Intervenções nutricionais em escolares. Revista Brasileira em Promoção da Saúde, 23(4), 297-306.

Anjos, R. H. D. D., Silva, J. A. D. S., Val, L. F. D., Rincon, L. A., \& Nichiata, L. Y. I. (2012). Diferenças entre adolescentes do sexo feminino e masculino na vulnerabilidade individual ao HIV. Revista da Escola de Enfermagem da USP, 46, 829-837.

Arasa Ferrer, H. (1991). Educación para la Salud: propuestas para su integración en la escuela. Programa Experimental de Educación para la Salud en la Escuela. Zaragoza: Diputación General de Aragón.

Bardin, L. (2011) Análise de Conteúdo. Trad. de Luís Antero Neto. Edições 70.

Barros, J. P. P. (2013). Biopolítica e educação: relações a partir das discursividades sobre saúde na escola. Educação \& Realidade, $38,361-381$.

Barros, J. P. P., \& Colaço, V. D. F. R. (2015). Drogas na Escola: análise das vozes sociais em jogo. Educação \& Realidade, 40, $253-273$.

Boff, L., \& Cuidar, S. (1999). Ética do humano-compaixão pela terra. Vozes.

Bogdan, R., \& Biklen, S. (1994). Investigação qualitativa em educação: uma introdução à teoria e aos métodos. Porto editora.

Brasil, E. G. M., Silva, R. M. D., Silva, M. R. F. D., Rodrigues, D. P., \& Queiroz, M. V. O. (2017). Promoção da saúde de adolescentes e Programa Saúde na Escola: complexidade na articulação saúde e educação. Revista da Escola de Enfermagem da USP, 51.

Brasil (1997) Ministério da Educação (MEC). Secretaria de Educação Fundamental (SEF). Parâmetros Curriculares Nacionais: introdução aos Parâmetros Curriculares Nacionais. MEC/SEF, 1997.

Brasil. (1998). Secretaria de Educação Fundamental. Parâmetros Curriculares Nacionais: terceiro e quarto ciclos: orientação sexual. MEC/SEF. http://portal.mec.gov.br/seb/arquivos/pdf/introducao.pdf

Brasil (2000). Ministério da Educação/Secretaria de Educação Básica Parâmetros Curriculares do Ensino Médio. Ciências da Natureza e suas Tecnologias. MEC/SEB. http://portal.mec.gov.br/seb/arquivos/pdf/blegais.pdf

Brasil (2005). Resolução no 03/GSIPR/CH/CONAD, de 27 de outubro de 2005. Aprova a Política Nacional sobre Drogas. Diário Oficial da União; 2005.

Brasil(2006). Ministério da Educação/Secretaria de Educação Básica Orientações Curriculares para o Ensino Médio. Ciências da Natureza, Matemática e suas Tecnologias. MEC/SEB.

Brasil (2009). Lei n. 12.015, de 7 de agosto de 2009. Altera o Título VI da Parte Especial do Decreto-Lei no 2.848 , de 7 de dezembro de 1940 - Código Penal, e o art. 1oda Lei no 8.072, de 25 de julho de 1990, que dispõe sobre os crimes hediondos, nos termos do inciso XLIII do art. 5o da Constituição Federal e revoga a Lei no 2.252, de 1o de julho de 1954, que trata de corrupção de menores [Internet]. Brasília; 2009 [citado 2016 ago. 18 ]. http://www.planalto.gov.br/ccivil_03/_Ato2007-2010/2009/Lei/L12015.htm

Brasil (2012). Conselho Nacional de Saúde do Brasil. Resolução CNS n. 466, de 12 de dezembro de 2012. Estabelecem as Diretrizes e normas regulamentadoras de pesquisa envolvendo seres humanos. http://conselho.saude.gov.br/resolucoes/2012/Reso466.pdf

Brasil. (2017) Ministério da Educação. Secretaria de Educação Básica. Base Nacional Comum Curricular. MEC. http://basenacionalcomum.mec.gov.br/

Brasil. (2013) Ministério da Educação. Secretaria de Educação Básica. Secretaria de Educação Continuada, Alfabetização, Diversidade e Inclusão. Conselho Nacional da Educação. Diretrizes Curriculares Nacionais Gerais da Educação Básica/ Ministério da Educação. Secretária de Educação Básica. Diretoria de Currículos e Educação Integral. MEC, SEB, DICEI, 2013. 542p. Disponível em: http://portal.mec.gov.br/docman/julho-2013-pdf/13677-diretrizes-educacaobasica-2013-pdf/file 
Brasil (2003) Ministério da Saúde. Instituto Nacional do Câncer. Programa Nacional de Controle do Tabagismo e Outros Fatores de Risco de Câncer Modelo lógico e avaliação. (2a ed.), Ministério da Saúde, Instituto Nacional do Câncer. https://www.inca.gov.br/publicacoes/livros/programa-nacional-decontrole-do-tabagismo-e-outros-fatores-de-risco-de-cancer

Brasil (2002) Ministério da Saúde. Secretaria de Política de Saúde. Área Técnica de Saúde do Adolescente e do Jovem. A saúde de adolescentes e jovens: uma metodologia de autoaprendizagem para equipe de atenção básica de saúde: módulo básico. Brasília: Ministério da Saúde. https://bvsms.saude.gov.br/bvs/publicacoes/0119saude_adole1.pdf

Brasil (2004) Ministério da Saúde. Secretaria de Vigilância em Saúde. Secretaria de Atenção à Saúde. Instituto Nacional de Câncer. Coordenação de Prevenção e Vigilância. Inquérito domiciliar sobre comportamentos de risco e morbidade referida de doenças e agravos não transmissíveis: Brasil, 15 capitais e Distrito Federal, 2002-2003. INCA. https://bvsms.saude.gov.br/bvs/publicacoes/inquerito_domiciliar_comportamentos_risco_doencas_transmissiveis.pdf

Brasil (1997). Secretaria de Educação Fundamental. Parâmetros curriculares nacionais: introdução aos parâmetros curriculares nacionais. Brasília.díponível em: http://portal.mec.gov.br/seb/arquivos/pdf/livro01.pdf

Bucharles, D. G., \& Mont'Alverne \& Catrib, A. M. F. (2013). Promoção da saúde e as escolas: como avançar. Brazilian Journal in Health Promotion, 26(3), 307-308.

Cajaiba, R. L. (2013). Percepção sobre sexualidade pelos adolescentes antes e após a participação em oficinas pedagógicas. Rev Elect Enseñanza Ciencias, 12(2), 234-42.

Campeiz, A. B., C. D. M., Campeiz, A. F., Silva, J. L. D., Freitas, L. A., \& Ferriani, M. D. G. C. (2020). A violência na relação de intimidade sob a ótica de adolescentes: perspectivas do Paradigma da Complexidade. Revista da Escola de Enfermagem da USP, 54.

Carrasquer, J., Ponz, A., Carrasquer, B., \& Álvarez, M. V (2019) Reflexiones acerca de la salud ambiental Reflections on environmental health.

Carta de Ottawa. (1986). Primeira conferência internacional sobre promoção da saúde. Ottawa.

Casemiro, J. P., Fonseca, A. B. C. D., \& Secco, F. V. M. (2014). Promover saúde na escola: reflexões a partir de uma revisão sobre saúde escolar na América Latina. Ciência \& saúde coletiva, 19, 829-840.

Civil, Casa. Lei no 8.069, de 13 de julho de 1990. (1990). Dispõe sobre o Estatuto da Criança e do Adolescente e dá outras providências. Brasília: Diário Oficial da União. http://www.planalto.gov.br/ccivil_03/leis/18069.htm

Czeresnia, D. \& Freitas, Cm (2003) (Org.). Promoção da Saúde: conceitos, reflexões, tendências. Fiocruz.

De Jesus, R. F., \& Garcia, R. N. (2019). Análise da abordagem de temas alusivos à saúde em documentos oficiais relacionados às práticas educativas em Ciências da Natureza. Revista Electrónica de Enseñanza de las Ciencias, 18(1), 79-103.

De Jesus'1, R. F., \& Sawitzki, R. L. (2017). Formação de professoras unidocentes e o tema transversal saúde: possibilidades e apontamentos. Revista Electrónica de Enseñanza de las Ciencias, 16(2), 341-361.

dos Reis Queiroz, V., \& de Almeida, J. M. (2017). Sexualidade na adolescência: potencialidades e dificuldades dos professores de ensino médio de uma escola estadual de Sorocaba. Revista da Faculdade de Ciências Médicas de Sorocaba, 19(4), 209-214.

Elicker, E. et al. (2015) Uso de álcool, tabaco e outras drogas por adolescentes escolares de Porto Velho-RO, Brasil. Epidemiologia e Serviços de Saúde, Brasília, 24, 399-410, http://www.scielo.br/pdf/ress/v24n3/2237-9622- ress-24-03-00399.pdf.

Eurípedes da Silveira, R., da Silva Santos, Á., \& Pereira, G. D. (2014). Consumo de álcool, tabaco e outras drogas entre adolescentes do ensino fundamental de um município brasileiro. Revista de Enfermagem Referencia, (2), 51.

Fazenda, I. C. A., \& Souza, F. C. D. (2012). Diálogos Interdisciplinares em Saúde e Educação: a arte do cuidar. Educação \& Realidade, 37, 107-124.

Furlanetto, M. F., Lauermann, F., Costa, C. B. D., \& Marin, A. H. (2018). Educação sexual em escolas brasileiras: revisão sistemática da literatura. Cadernos de Pesquisa, 48, 550-571.

Gavidia C. V., \& Talavera O; M. (2012). La construcción del concepto de salud. Didáctica de Las Ciencias Experimentales Y Sociales. ‥ ${ }^{\circ} 26.2012,161-175$ Gil, A. C. (2002). Como elaborar projetos de pesquisa (Vol. 4, p. 175). Atlas.

Gavidia Catalán, V., Agud, D., Talavera, M., \& Pérez de Eulate González, L. (2013). Las competencias en educación sexual en el currículo de la educación secundaria obligatoria española. Enseñanza de las ciencias, (Extra), 01525-1530.

Gavidia Catalán, V. (1993). Consideraciones sobre la formación inicial del profesorado en Educación para la Salud. Didáctica de las Ciencias Experimentales y Sociales, 1993, vol. 7, p. 59-70.

Guedes, D. P., \& Lopes, C. C. (2010). Validation of the Brazilian version of the 2007 youth risk behavior survey. Revista de Saúde Pública, 44(5), 840-850.

Günther, H. (2006). Pesquisa qualitativa versus pesquisa quantitativa: esta é a questão? Psicologia: teoria e pesquisa, 22(2), 201-209.

Jacobson, L. D. S. V., Andrade, C. L. T. D., Carmo, C. N. D., Mourão, D. D. S., \& Hacon, S. D. S. (2009). Trend in mortality due to external causes in the State of Espírito Santo, Brazil, from 1994 to 2005. Revista Brasileira de Epidemiologia, 12, 82-91.

Juzwiak, C. R., Castro, P. M. D., \& Batista, S. H. S. D. S. (2013). A experiência da Oficina Permanente de Educação Alimentar e em Saúde (OPEAS): formação de profissionais para a promoção da alimentação saudável nas escolas. Ciência \& saúde coletiva, 18, 1009-1018.

Horta, N. D. C., \& Sena, R. R. D. (2011). La salud en el cotidiano de jóvenes residentes en un barrio popular de Belo Horizonte, MG, Brasil. Revista da Escola de Enfermagem da USP, 45(spe2), 1673-1678. 
Krug, E. G., Mercy, J. A., Dahlberg, L. L., \& Zwi, A. B. (2002). The world report on violence and health. The lancet, 360(9339), $1083-1088$.

Lahire, B. (2002). Homem plural: os determinantes da ação. Vozes Editora.

Lara, S., Salgueiro, A. C. F., Lara, M., Puntel, R. L., \& Folmer, V. (2013). Educação e saúde no contexto escolar: Saúde cardiovascular como tema gerador no curso normal médio. Revista Electrónica de Enseñanza de las Ciencias, 12(1).

Lobo, L. A., \& Barbosa, M. C. L. (2017). Álcool e drogas: Um problema vivido por adolescentes usuários em um município do sudoeste da Bahia. ID on line REVISTA DE PSICOLOGIA, 10(33), 32-42.

Lopes, M. C. D. L., Oliveira, R. R. D., Silva, M. D. A. P. D., Padovani, C., Oliveira, N. L. B. D., \& Higarashi, I. H. (2020). Tendência temporal e fatores associados à gravidez na adolescência. Revista da Escola de Enfermagem da USP,54.

Lopes Neto, A. A. (2005). Bullying: comportamento agressivo entre estudantes. Jornal de pediatria, 81, s164-s172.

Lüdke, M., \& André, M. (1986). Pesquisa em educação: abordagens qualitativas.

Marinho, J. C. B., \& Silva, J. A. D. (2019). Análise moral e ética no cuidado com a saúde de adolescentes cabo-verdianos e brasileiros referente ao consumo de cigarros, álcool, drogas e anabolizantes. Ciência \& Educação (Bauru), 25, 297-315.

Marques, V. R. B. (1994). A medicalização da raça: Médicos. Educadores e Discurso Eugênico. Editora da Unicamp.

Martins, L.; Dimoulis, D. (2010). Teoria Geral dos Direitos Fundamentais. Editora Revista dos Tribunais.

Melo, J. A. C. (1976). A prática de saúde e a educação. 1976 (Tese (Doutorado em Saúde Pública) - Faculdade de Ciências Médicas da Universidade Estadual de Campinas, Campinas).

Melo, L. P. D., \& Oliveira, A. L. D. O. (2017). Viver Através de Projetos de Saúde: práticas de educação em saúde no Brasil. Educação \& Realidade, 42, 961980 .

MIRA, F. D. (2007) Capacitação de professores em alimentação saudável na rede municipal de Mutuípe, Bahia: alcances e limitações. 120 f. Dissertação (Mestrado em Alimento, Nutrição e Saúde) - Escola de Nutrição, Universidade Federal da Bahia, Salvador.

Monteiro, C. A., Mondini, L., Souza, A. L. M. D., \& Popkin, B. M. (1995). Da desnutrição para a obesidade: a transição nutricional no Brasil. In Velhos e novos males da saúde no Brasil: a evolução do país e de suas doenças (pp. 247-55).

Moreira, B. L. da R.; Folmer, (2015) V. Percepções de professores de ciências e educação física acerca da educação sexual na escola. Experiências em Ensino de Ciências. 10(3).

Moreira, F. G., Silveira, D. X. D., \& Andreoli, S. B. (2006). Redução de danos do uso indevido de drogas no contexto da escola promotora de saúde. Ciência \& Saúde Coletiva, 11(3), 807-816.

Moreno, N. Saúde e Educação (1946) Arquivo de Higiene e Saúde Pública, v. 11, n. 29, p. 425-35, 1946.

Moreira, B. L. R., Rocha, J. B. T., Puntel, R. L., Folmer, V. (2011). Educação sexual na escola: implicações para a práxis dos adultos de referência a partir das dúvidas e curiosidades dos adolescentes. Revista Electrónica de Enseñanza de las Ciencias, 10(1), 64-83.

Mota, R. S., Gomes, N. P., Oliveira, J. F. D., Campos, L. M., Araújo, G. S. D., Gusmão, M. E. N., \& Carneiro, J. B. (2019). Situação sociodemográfica e de saúde em adolescentes escolares segundo o sexo. Revista Brasileira de Enfermagem, 72, 1007-1012.

Moura, L. R. D., Torres, L. M., Cadete, M. M. M., \& Cunha, C. D. F. (2018). Fatores associados aos comportamentos de risco à saúde entre adolescentes brasileiros: uma revisão integrativa. Revista da Escola de Enfermagem da USP, 52.

Müller, A. C., Paul, C. L., \& Santos, N. I. S. D. (2008). Prevenção às drogas nas escolas: uma experiência pensada a partir dos modelos de atenção em saúde. Estudos de Psicologia (Campinas), 25(4), 607-616.

Neves, F. H. G., \& Queiroz, P. P. D. (2020). O Ensino de Ciências e a Saúde: por uma Docência Intercultural e Crítico-Reflexiva na Escola Básica. Ciência \& Educação (Bauru), 26.

Nogueira, M. J., Barcelos, S., Barros, H., \& Schall, V. T. (2011). Criação compartilhada de um jogo: um instrumento para o diálogo sobre sexualidade desenvolvido com adolescentes. Ciência \& Educação (Bauru), 17, 941-956.

Oliva, J. M. (2011). Difficulties of secondary school teachers implicating in the reading, innovation and research in science education (I): The problem to begin with. Revista Eureka sobre enseñanza y divulgación de las ciencias, 8(1).

Pereira, A. P. D., \& Sanchez, Z. M. (2020). Características dos Programas escolares de Prevenção ao Uso de Drogas no Brasil. Ciência \& Saúde Coletiva, 25, 3131-3142.

Pereira, M.G. (1995) Epidemiologia: teoria e prática. Guanabara Koogan.

Pigozi, P. L., \& Machado, A. L. (2019). Os cuidados da Estratégia Saúde da Família a um adolescente vítima de bullying: uma cartografia. Ciência \& Saúde Coletiva, 25, 353-363.

Pueyo, A., Carrasquer, J., Álvarez, M. V., \& Ponz, A. (2016). El Centro de Salud como Escuela para la Salud. Avaliação de Processos Educacionais em Saúde: Tendências e Inovações, 220-244. 
Research, Society and Development, v. 10, n. 9, e47410917766, 2021

(CC BY 4.0) | ISSN 2525-3409 | DOI: http://dx.doi.org/10.33448/rsd-v10i9.17766

Reis, A. A. C. D., Malta, D. C., \& Furtado, L. A. C. (2018). Desafios para as políticas públicas voltadas à adolescência e ju ventude a partir da Pesquisa Nacional de Saúde do Escolar (PeNSE). Ciência \& Saúde Coletiva, 23, 2879-2890.

Rocha, R. L. P., \& Folmer, V. (2011). Educação sexual na escola: implicações para a práxis dos adultos de referência a partir das dúvidas e curiosidades dos adolescentes. Revista Electrónica de Enseñanza de las Ciencias, 10(1), 64-83.

Rocha, A. D. S., \& Facina, V. B. (2017). Professores da rede municipal de ensino e o conhecimento sobre o papel da escola na formação dos hábitos alimentares dos escolares. Ciência \& Educação (Bauru), 23, 691-706.

Santos, L. A. D. S. (2005). Educação alimentar e nutricional no contexto da promoção de práticas alimentares saudáveis. Revista de Nutrição, $18,681-692$.

Santos, E. G. D., \& Sadala, M. D. G. S. (2013). Alteridade e adolescência: uma contribuição da psicanálise para a educação. Educação \& Realidade, 38, 555568.

Saraiva, P. L. (1983). Garantia constitucional dos direitos sociais no Brasil. Forense.

Schmitz, B. D. A. S., Recine, E., Cardoso, G. T., Silva, J. R. M. D., Amorim, N. F. D. A., Bernardon, R., \& Rodrigues, M. D. L. C. F. (2008). A escola promovendo hábitos alimentares saudáveis: uma proposta metodológica de capacitação para educadores e donos de cantina escolar. Cadernos de Saúde Pública, 24, s312-s322.

Silva, B. R. V. S., Silva, A. O. D., Passos, M. H. P. D., Soares, F. C., Valença, P. A. D. M., Menezes, V. A. D., \& Santos, C. D. F. B. F. (2018). Autopercepção negativa de saúde associada à violência escolar em adolescentes. Ciência \& Saúde Coletiva, 23, 2909-2916.

Silveira, L. S. D. (2004). Prevenção de doenças e promoção da saúde: diferenciais estratégicos na conjuntura do mercado de saúde suplementar (Doctoral dissertation).

Silveira, R. E. D., Santos, Á. D. S., \& Pereira, G. D. A. (2014). Consumo de álcool, tabaco e outras drogas entre adolescentes do ensino fundamental de um município brasileiro.

Soares, C. B., \& Jacobi, P. R. (2000). Adolescentes, drogas e AIDS: avaliação de um programa de prevenção escolar. Cadernos de Pesquisa, (109), $213-237$.

Soares, F. R. R., Oliveira, D. I. D. C., Torres, J. D. M., Pessoa, V. L. M. D. P., Guimarães, J. M. X., \& Monteiro, A. R. M. (2020). Motivações do consumo de drogas entre adolescentes: implicações para o cuidado clínico de enfermagem. Revista da Escola de Enfermagem da USP, 54.

Sobral, N. A. T., \& Santos, S. M. C. D. (2010). Proposta metodológica para avaliação de formação em alimentação saudável. Revista de Nutrição, 23(3), 399415.

Talavera, M., \& Catalan, V. G. (2013). Percepción de la educación para la salud en el personal docente y el sanitario. Didáctica de las ciencias experimentales y sociales, (27).

World Health Organization (WHO) (1995). Physical status: the use and interpretation of anthropometry. Report of a WHO Expert Committed. WHO Technical Report Series 584. 1995. WHO

World Health Organization (2004) Global strategy on diet, physical activity and health. WHO.

World Health Organization. (2009) Preventing intimate partner and sexual violence against women. WHO 